\title{
As manifestações linguísticas e culturais na construção de uma cidadania global: o caso do ensino de português como língua adicional
}

\author{
Luciana Graça ${ }^{1}$ \\ Camões, I.P./ Universidade de Toronto \\ Anabela Rato ${ }^{2}$ \\ Universidade de Toronto
}

Resumo: Este texto reflete sobre como poderão atividades didáticas sobre manifestações linguísticas e culturais, representativas da diversidade e da riqueza do mundo lusófono, contribuir para a construção de uma cidadania global, na aula de português como língua adicional. Para tal, e, depois de uma breve introdução, numa primeira secção de natureza mais teórica (seç̧ão 2), exploraremos o nosso objeto de estudo, inscrevendo-o no campo da educação, em geral, e no do ensino de línguas, em particular, e terminaremos esta secção com uma reflexão sobre a forma como uma abordagem pluricêntrica no ensino de português poderá contribuir para esse objetivo. Na secção seguinte (secção 3), apresentaremos algumas das atividades e alguns dos projetos realizadas, sob tal lógica de atuação, que consideramos terem sido importantes elementos para uma maior consciencialização, junto dos nossos alunos, sobre o reconhecimento e a valorização das diferenças, em distintos planos, no mundo lusófono.

Palavras-chave: Cidadania global; Português como Língua Adicional; Pluricentrismo.

Title: Linguistic and cultural manifestations in the teaching of Portuguese as an additional language for the construction of a global citizenship

Abstract: Our text reflects on how learning activities on linguistic and cultural manifestations, and representative of the diversity and richness of the Portuguese-speaking world, can contribute to the construction of a global citizenship in language learners in the teaching of Portuguese class as an additional language. To this end, and in a first section of a more theoretical nature (section 2), we will explore, synthetically, our object of study, inscribing it in the field of education, in general, and in the teaching of languages, more in particular. We will end this section with a reflection on how a pluricentric approach to Portuguese can contribute to this goal. In the following section (section 3), we will present some of the activities and projects that we have developed that during our academic career in higher education. We consider were that these activities are important elements to create more awareness, among our students, about the recognition and appreciation of differences, in different levels, in the Portuguese-speaking world.

Keywords: Global citizenship; Portuguese as an Additional Language; Pluricentrism.

\footnotetext{
${ }^{1}$ Orcid: http://orcid.org/0000-0003-1384-9540. E-mail: luciana.graca@utoronto.ca.

${ }^{2}$ Orcid: http://orcid.org/0000-0001-7822-8580. E-mail: anabela.rato@utoronto.ca.
} 


\section{Introdução}

A partir de uma nossa inicial reflexão sobre a perspetiva educativa de uma cidadania global, em geral, e nas aulas de língua, mais em particular, como promotora de um novo modelo de cidadania, ativamente empenhada na construção de um mundo mais equitativo e sustentável, propõe-se esta nossa contribuição a apresentar a abordagem pluricêntrica no ensino de português, nas suas vertentes linguística e cultural, como um importante contributo para a construção de uma tal cidadania, nas aulas de português como língua adicional. $^{3}$ Por outras palavras, como poderão a língua portuguesa e a cultura do mundo lusófono ser utilizadas como elementos fundamentais para a construção de alunos ativamente críticos, em relação ao mundo, ao reconhecerem a sua diversidade e a sua respetiva riqueza? Para respondermos a esta pergunta, apresentaremos, assim, um conjunto de atividades por nós concebidas, e já aplicadas, em sala de aula, ao longo do nosso percurso profissional no ensino superior, como professoras de português como língua adicional. Com efeito, o papel e a importância de cada um de nós no mundo tem vindo a ser cada vez mais discutido nas mais distintas esferas, como as sociais, as civis, as económicas, as políticas, entre muitas outras. $E$, em todas essas discussões, a necessidade e a urgência de uma preocupação efetiva com a promoção de uma cidadania ativa têm sido uma constante, até devido à atual realidade da sociedade mundial, e, mormente, para construção do próprio indivíduo, que cada vez mais procura compreender, e melhorar, a sua posição em relação ao mundo. Ora, e naturalmente, o ensino, em geral, e o ensino de línguas, em particular, não poderiam ficar à margem de tais movimentos transformadores.

\section{Pressupostos teóricos: cidadania global e pluricentrismo no ensino de línguas}

\section{A cidadania global na educação e no ensino de línguas}

A cidadania global constitui-se, grosso modo, como uma perspetiva educativa promotora de um novo modelo de cidadania, ativamente empenhada na construção de um mundo mais equitativo e sustentável, apostando-se, nomeadamente, no respeito pelos direitos humanos individuais e sociais, na valorização da diversidade e no consumo responsável. E, atualmente, assume uma particular relevância à luz, muito particularmente, dos conhecidos Objetivos de Desenvolvimento Sustentável, ${ }^{4}$ em que o quarto é exclusivamente dedicado, precisamente, à promoção de uma "Educação de Qualidade"

\footnotetext{
${ }^{3}$ Uma língua adicional é percecionada como um acréscimo à(s) língua(s) que o aluno já usa, e que fazem parte da sua vida.

4 Para mais detalhes, consultar "17 Objetivos de Desenvolvimento Sustentável”. Disponível em: https://www.unescoportugal.mne.pt/pt/temas/objetivos-de-desenvolvimento-sustentavel/os-17-ods. Acesso em: 14 ago. 2020.
} 
(UNESCO, 2015)..$^{5}$ Afinal, e para uma salutar convivência em sociedade, igualmente relevantes são os valores humanos, como os de cidadania, solidariedade, altruísmo, civismo, ética, entre muitos outros. É neste contexto que a educação para a cidadania poderá assumir um papel de relevante destaque, por poder contribuir de forma significativa para a formação de cidadãos mais reflexivos e mais partícipes na vida coletiva, e para a promoção de uma sociedade respeitadora dos mais elementares valores humanos. Nas palavras de Fernando Reimers (2017), "[a] educação para a cidadania global é essencial para a criação de um mundo sustentável - um mundo sem pobreza ou fome e onde todos têm acesso à saúde e à educação". Acredita-se mesmo, assim, que seja esta uma das funções da escola e, aliás, uma missão de todos os professores, independentemente da(s) disciplina(s) curricular(es) por que sejam responsáveis: a produção de conhecimento e, em simultâneo, o próprio desenvolvimento de cidadãos, no seu sentido mais pleno (MATTOS, 2011). Daí também, portanto, a importância de em cada disciplina curricular serem propostas atividades de aprendizagem efetivamente significativas, inclusive, para o desenvolvimento, nos discentes, de uma consciência robusta quanto ao contexto, seja este mais local ou global. Afinal, "[t]he individual is not an island but a being of relationships" (EDNIR, 2015, p. 73).

E se a instituição de ensino por natureza, um dos espaços mais importantes para a preparação das pessoas para o convívio e a interação com outras línguas e culturas, não deixa a aula de línguas, em geral, e de língua adicional, em particular, de ocupar também um papel crucial nesta questão. Aliás, são numerosas as vozes a afirmar poder o ensino de uma língua adicional assumir, precisamente, "um papel [instrumental] e pragmático para a construção da cidadania" (ORTIZ; FINARD, 2015; TILIO, 2014); e tal desde logo por aí tenderem a estar presentes aprendentes de origens tão numerosas quanto diversas, que procuram comunicar entre si. E, como sabemos, é através do diálogo, e também da empatia, que os sujeitos se descentralizam, se colocam no lugar do outro e, inclusive, se reconstroem. É (também) nestes contextos que somos estimulados a desenvolver novas competências relacionadas não só com a língua como também com a cultura e com o contacto com o Outro. E, a este respeito, aqui recordamos o conceito de competência comunicativa intercultural (BYRAM, 2009, p. 321), aqui recordando algumas palavras de Fantini a tal respeito (2009, p. 458): "each individual possesses a native communicative competence (...) and during intercultural contact (...) those who choose to acquire a second communicative competence develop intercultural competence" . A competência comunicativa intercultural compreende, assim, a presença de uma competência comunicativa própria, o desenvolvimento de uma segunda competência comunicativa, e o que nasce do confronto propriamente dito das duas, ou seja, o desenvolvimento da competência intercultural per se.

\footnotetext{
${ }^{5}$ Recordamos, mais especificamente, a Meta 4.7. dos Objetivos do Desenvolvimento Sustentável: “Até 2030, garantir que todos os alunos adquiram conhecimentos e habilidades necessárias para promover o desenvolvimento sustentável, inclusive, entre outros, por meio da educação para o desenvolvimento sustentável e estilos de vida sustentáveis, direitos humanos, igualdade de gênero, promoção de uma cultura de paz e não violência, cidadania global e valorização da diversidade cultural e da contribuição da cultura para o desenvolvimento sustentável". Disponível em: https://ods.imvf.org/wp-content/uploads/2018/12/Recursosods-objetivos-aprendizagem.pdf, acesso em: 14 ago. 2020.
} 
E só assim, sendo nós, portanto, competentes na comunicação intercultural, nos vários espaços comuns e de contacto com a grande diversidade humana, ultrapassamos de forma inata uma rígida divisão entre saberes linguísticos e culturais, já que, devido à forma como atualmente ocorre a mobilidade humana, "nos colocaremos em acções comunicativas inevitavelmente plurilinguísticas e pluriculturais que apelam por uma competência que não se satisfaz com um saber sobre línguas ou culturas específicas, mas também com um saber ser" (CARDOSO, 2017). É também neste contexto que alude o Quadro Europeu Comum de Referência para as Línguas (Conselho Europeu, 2001, p. 17), assim, à importância do desenvolvimento de uma competência plurilingue e pluricultural "complexa, mas una, resultado do desenvolvimento simultâneo, em graus diferentes, da competência global de comunicação em várias línguas e da experiência em culturas diversificadas". E, a este respeito, adquire igualmente particular relevância o próprio conceito de mediação intercultural, assente na ideia de transformação e de prevenção versus resolução (AA.VV., 2008; Barrett, 2017; Caride, 2016; Conselho da Europa, 2016, 2018; Vieira e Vieira, 2016 ); por outras palavras, e diante de sociedades naturalmente plurais, a mediação intercultural favorece o estabelecimento de pontos de contato entre o que é diferente ( $A A$. VV., 2008), contribuindo, assim, para a comunicação, a relação e a inclusão, muito particularmente, de pessoas ou grupos culturalmente distintos. E será, precisamente, esta mestria que permitirá a cada indivíduo, enquanto ator social, "interagir linguística e culturalmente em diversos contextos linguísticos" (CARDOSO, 2017). À luz destas conceções, facilmente se compreende, assim, a importância indiscutível do papel que pode um professor de línguas, em geral, e o de uma língua adicional, mais especificamente, assumir, para um desenvolvimento o mais completo possível de um aprendente, nas suas mais variadas esferas de ação. E para um tal desenvolvimento, a língua e a cultura precisarão, sempre, de serem concebidas de forma interrelacionada. Afinal, e como nos recorda Castro, "se ensinarmos língua, sem ensinarmos a cultura na qual ela funciona, estamos a ensinar signos sem sentido" (2004, p. 18). E fora, precisamente, tendo estas últimas palavras também em mente, e atendendo, ainda, ao facto de sermos nós próprias professoras de português, que concebemos a secção seguinte, em que nos deteremos sobre a forma como poderá uma abordagem pluricêntrica do português, nas suas dimensões linguística e cultural, ser também um importante contributo para a construção de uma cidadania global, nas aulas de português como língua adicional.

A abordagem pluricêntrica no ensino de português para a construção de uma cidadania global

"Português, Língua Pluricêntrica do século XXI". Assim se intitulara um colóquio internacional ocorrido já em 2015, em Portugal, com o objetivo de se "promover uma discussão em torno de questões de política linguística, em diferentes facetas, dando um 
relevo particular (...) à emergência de normas nacionais com novos centros de difusão". 6 Ora, como anunciado no título e nos principais objetivos do encontro, a verdade é que de facto se ultrapassara, há largos anos, o bicentrismo que gerira a língua portuguesa, até ao início do século XXI, considerando-se que apenas Portugal e o Brasil poderiam regular a língua e sobre esta decidir, a nível do exercício de padronização do idioma (OLIVEIRA, 2015). Foi com o Acordo Ortográfico de 1990 e com criação da Comunidade dos Países de Língua Portuguesa (CPLP) que se iniciara, precisamente, a fase inicial do pluricentrismo, e em que se fizeram também ouvir os Países Africanos de Língua Portuguesa (PALOP), nas políticas linguísticas para o português. Porém, não deixa também de ser verdade que permanecem, ainda, duas normas codificadas, a brasileira e a portuguesa. Com efeito, e apesar dos cada vez mais recorrentes discursos sobre as diversidades linguística e cultural do mundo lusófono, ainda não foram estes por completo seguidos nem pelos designados manuais didáticos nem pelas práticas de ensino propriamente ditas. A respeito dos materiais didáticos, são estas algumas das principais falhas que lhes são apontadas: uma adoção de abordagens antiquadas nos cadernos de exercícios, uma enorme presença de textos elaborados com fins apenas didáticos, uma visão cindida entre Portugal e Brasil, ignorandose o pluricentrismo da língua, o seu estatuto oficial nos Estados-membros da CPLP e o interesse demonstrado por parte, por exemplo, de regiões administrativas, como Macau (FERNANDES; SILVA, 2019, p. 310).

Ora, devido desde logo à riqueza da lusofonia, nas suas mais variadas vertentes, e em todas as suas demais potencialidades, em campos vários, e à luz, ainda, das considerações tecidas na anterior subsecção, facilmente se reconhece a importância, e a premência, de que novas ações, e novos esforços, ocorram, para que não só seja a lusofonia uma realidade (mais) constante nas salas de aula como também seja a cidadania global uma presença (mais) assídua nestes mesmos espaços, com uma atenção mais constante, e atenta, à diversidade do mundo lusófono, nas suas mais variadas formas de expressão. O que, precisamente, vai ao encontro do que defende a UNESCO, ao acreditar que, num mundo cada vez mais globalizado, é necessário educar crianças e jovens para que se sintam parte de uma comunidade mais ampla, e em que os níveis local, nacional e global estejam conectados. Um efetivo reconhecimento da riqueza do mundo lusófono terá de passar, assim, e necessariamente, por uma sua valorização efetiva, que, no caso do ensino, consistirá em levá-la em permanência para a sala de aula, explorando-a nas suas mais distintas dimensões, e sabendo-se que só desta forma se estará também a utilizar o espaço da sala de aula para a construção de uma cidadania mais plena. Desta forma, estar-se-á a (in)formar os alunos no respeito pela diferença, que, e no caso específico do ensino do português como língua adicional, poderá passar, a título tão-só exemplificativo, por uma discussão sobre a variação da língua portuguesa (JOUËT-PASTRÉ, 2010), a exploração de materiais e recursos didáticos que incorporem as diversidades linguística e cultural da lusofonia (OLIVEIRA; JESUS, 2018; SIGNORI, 2015), e com uma representatividade

\footnotetext{
${ }^{6}$ Para mais detalhes, consultar a página eletrônica da CPLP (http://www.clpl.org - acesso em: 14 ago. 2020.
} 
semelhante, no que se refere a todos os países envolvidos, e o estudo das diferentes formas como um mesmo acontecimento cultural é celebrado em diferentes partes do mundo lusófono, estabelecendo-se também as devidas conexões com a própria história que une os países de língua oficinal portuguesa. A secção seguinte será dedicada à apresentação de algumas das atividades e de alguns dos projetos que levámos a cabo, ao longo do nosso percurso profissional no ensino superior, como professoras de português como língua adicional, de molde a contribuirmos, precisamente, para a perspetiva educativa a que temos vindo a fazer menção. Estas propostas que apresentámos aos nossos alunos inscrevem-se, assim, numa abordagem pluricêntrica da língua portuguesa - com o enfoque, mais especificamente, e como temos referido, numa vertente plurilinguística e pluricultural -, e com os quais esperamos conseguir demonstrar, portanto, como a cidadania global poderá ser (também) uma construção linguística e cultural, no contexto específico das aulas de português como língua adicional.

\section{A língua e a cultura, no espaço lusófono, no processo de construção de uma cidadania global}

Em que medida poderão a língua portuguesa e a cultura lusófona contribuir para a construção de uma cidadania global, no contexto particular das aulas de português como língua adicional? Para demonstrarmos como, na nossa prática de ensino universitário, temos procurado responder a tal questão, passaremos, seguidamente, à apresentação de algumas das propostas a que temos lançado mão, em sala de aula, para contribuirmos para tal objetivo. Como já referido, selecionaremos trabalhos que se inscrevem, essencialmente, numa abordagem plurilinguística e pluricultural do português, e em que foram tidas também em conta as próprias origens linguísticas dos discentes, e que foram realizados, mais especificamente, numa universidade pública na América do Norte, onde há uma grande comunidade de falantes de língua portuguesa, sendo o público formado por um grupo heterogéneo de falantes de português (mais especificamente, língua segunda, língua estrangeira e língua de herança ${ }^{7}$ ) e que têm o inglês como a sua língua dominante.

Uma abordagem plurilinguística - português, um nome singular para uma realidade plural

A adoção de uma abordagem plurilinguística no ensino do português representa,

\footnotetext{
7 Aqui ficam breves definições: i) a língua segunda, aprendida após a primeira língua estar desenvolvida, designa a língua que a pessoa aprende, quando vai viver para outro país, já que dela precisa para comunicar, ou a que é também falada no seu país como oficial, como em países como Timor Leste, Cabo Verde, Moçambique e Angola, sendo que, nestes casos, as línguas primeiras são as línguas autóctones e o português é aprendido a partir da idade escolar ; ii) a língua estrangeira representa uma língua aprendida em contexto em que não é falada localmente/nacionalmente ou não é língua oficial; e iii) a língua de herança, na diáspora, designa a língua adquirida junto da família e da comunidade de origem deslocada, num ambiente linguístico maioritário; e, por isso, o seu uso tende a ser restrito a ambientes familiares e/ou a pequenos grupos sociais (MELO-PFEIFER, 2018).
} 
grosso modo, o estudo da diversidade da língua, em todas as suas concretizações, dando-se, portanto, igual relevo quer às variedades portuguesas quer às respetivas variedades nacionais e regionais (JOÜET-PASTRÉ, 2010; SOLLAI; PARMA, 2018). E, entre os principais objetivos gerais de aprendizagem, encontramos, por exemplo: familiarizar os alunos com variedades-padrão e não padronizadas de português; reconhecer diferenças e semelhanças a diferentes níveis linguísticos - fonológico, morfológico, sintático e lexical - entre variedades nacionais da língua portuguesa; promover a consciencialização sobre a riqueza da variação dialetal e a compreensão das variedades linguísticas; discutir mitos sobre o português (como o conhecido "mito da língua única"); e desenvolver a própria competência plurilíngue dos alunos e ampliar o seu repertório linguístico (RATO \& GRAÇA, no prelo). Implica, ainda, e naturalmente, a própria seleção das variedades linguísticas que são mais relevantes no contexto de aprendizagem específico dos alunos. E, por outro lado, procura-se, igualmente, reforçar a utilização de materiais autênticos, que representem situações reais de comunicação, de todos os países de língua portuguesa (com o recurso, por exemplo, a materiais audiovisuais de televisão, rádio, internet; e a textos de jornais, revistas, anúncios, entre outros suportes), conscientes também da importância de tal para a formação de um aluno-cidadão mais atento ao mundo que o rodeia. Com as três atividades que a seguir apresentaremos, procuraremos exemplificar, precisamente, a forma como procuramos contribuir no contexto de tal lógica de atuação.

Proposta 1. Numa disciplina de pronúncia em língua portuguesa, após a devida exposição a distintas variedades nacionais e regionais do português, através, entre outros recursos, da visualização de vídeos e áudios representativos, apresentou-se à turma o projeto de investigação "Variação fonológica no mundo lusófono", em que o objetivo principal consistia em identificar a ocorrência de variação fonético-fonológica do português. Este projeto, que se materializara numa apresentação oral breve, compreendeu as duas seguintes etapas: i) seleção de uma amostra de fala autêntica exemplificativa de uma variedade nacional do português (como o europeu, o brasileiro, o angolano, o moçambicano, o cabo-verdiano) ou de uma variedade de sotaque regional (como, por exemplo, o sotaque carioca - do Rio de Janeiro - ou o sotaque são micaelense - dos Açores); e ii) identificação e descrição dos fenómenos de variação fonética que exemplificassem tal variedade. $E$, com esta atividade, mais do que fazer-se apenas o reconhecimento das distintas variedades do português, foi também trabalhada a valorização de cada uma; e, por consequência, também daqueles que as falam, contribuindo assim para a desmitificação de que a língua portuguesa é singular.

Proposta 2. Numa disciplina sobre língua portuguesa e sociedade, procedeu-se ao estudo da variação do português como língua de herança (PLH), tendo-se (também) tido muito particularmente em conta o caso da cidade da universidade em questão, com a proposta da realização de uma entrevista a bilíngues de português-inglês (falantes de herança de português da primeira geração). Com o objetivo de aplicar os conhecimentos 
adquiridos e um método específico de investigação, o da entrevista sociolinguística, e primordialmente, refletir sobre a sua própria situação sociolinguística, foram analisados quer numerosos quer variados aspetos linguísticos; a saber, e tão-só a título exemplificativo: a alternância intra-frásica e inter-frásica de código linguístico entre o português europeu centro-meridional (língua de herança) e o inglês canadiano (língua dominante), a conjugação verbal (presente do indicativo, terceira pessoa do plural) no dialeto micaelense, a realização de sujeito nulo no dialeto carioca, a redução vocálica no dialeto centro-meridional, e o uso dos sufixos de diminutivo no português LH. Com mais esta atividade, não só a nossa atenção se centrou sobre a riqueza das variedades da língua portuguesa como também foi possível conduzir os alunos a um conhecimento mais aprofundado do seu contexto mais imediato, além do espaço físico da sala de aula universitária.

Proposta 3. Ainda na mesma disciplina sobre língua portuguesa e sociedade, para se reconhecer a diversidade de idiomas e dialetos que constituem a vida destes estudantes, situados num contexto multicultural e multilinguístico, no que diz também respeito às variedades do português, e para analisar a própria situação sociolinguística da língua portuguesa na cidade da universidade em questão, foi proposta a elaboração de uma descrição da paisagem linguística portuguesa nessa mesma cidade. Com efeito, os estudos das paisagens linguísticas, que se têm vindo a expandir, mormente, na última década (BLOMMAERT, 2012; MAHER, 2013), têm procurado compreender, grosso modo, como as línguas são disponibilizadas e representadas em locais e espaços públicos, permitindo a compreensão sobre as funções de cada língua naquele mesmo contexto (BLOMMAERT, 2012; MAHER, 2013). No nosso caso, e mais especificamente, pedimos aos alunos que construíssem um portefólio quer com fotografias de uma determinada área urbana (uma rua ou um bairro) de sinalização (oficial, pública e/ou comercial) escrita em português quer com uma reflexão sobre a sua própria interpretação da paisagem semiótica selecionada. E a verdade é que a reação dos alunos foi deveras positiva, tendo os ganhos sido não só numerosos quanto variados. De facto, além da parte pedagógica, propriamente dita, associada a esta atividade, a verdade também é que voltaram os discentes para a sala de aula com um conhecimento mais aprofundado sobre os espaços físicos que tinham conhecido, pelo menos de uma forma mais aprofundada e com um novo olhar sobre a sua própria situação sociolinguística numa cidade caracterizada pela coexistência de várias línguas de herança, incluindo diferentes variedades nacionais como o português europeu, brasileiro e angolano (as mais representativas neste contexto) e regionais. Mostraram-se mais atentos à realidade em que se movimentaram, para realizar o seu trabalho, e o próprio interesse em conhecer mais a presença lusófona na cidade em que moram sofreu também um considerável aumento.

Uma abordagem pluricultural - lusofonia, um mundo de culturas

Perante o reconhecimento de que a sala de aula é um espaço pluricultural, 
facilmente se compreende a importância de se utilizar desde logo esse mesmo contexto para o desenvolvimento de competências que favoreçam a mediação cultural, e que será, na verdade, muito mais relevante, fora do espaço académico. Ora, sabendo-se também que o ensino e a aprendizagem de uma língua vão muito mais além do que uma mera transmissão e apreensão de estruturas formais e de regras de utilização de tais estruturas (MENDES, 2015 , p. 203), afigura-se como particularmente profícuo usar também a aula de língua adicional para explorar, em todas as suas potencialidades, as múltiplas culturas que estão inerentemente associadas a uma língua. E, ao falarmos de um trabalho sobre a cultura, falamos também, por exemplo, da inclusão de temas relacionados não só com as dimensões geográficas e sociais das variedades da língua, no caso, portuguesa, como também com os aspetos culturais e sociais do mundo lusófono (MENDES, 2014, 2015; OLIVEIRA; JESUS, 2018), e que, pelo confronto de culturas, não deixará de permitir um maior conhecimento de si próprio e do Outro. Ora, as propostas de trabalho seguintes, levadas também a cabo em disciplinas de língua, com alunos com diversos níveis de proficiência - desde alunos de iniciação (projetos 1, 2 e 3) a alunos de nível intermédio e avançados (projetos 1, 2 e 3) -, inscrevem-se, precisamente, nesta lógica de atuação. Acrescentamos, ainda, e desde já, que, e apesar de serem atividades de produção escrita, recorremos também, para a sua preparação, a atividades de desenvolvimento das capacidades orais dos alunos, como chuvas de ideias e discussões.

Proposta 1. O trabalho "Projetos de desenvolvimento sustentável que fazem a diferença, em países de língua portuguesa" foi pelas docentes concebido na esteira das preocupações que conduziram as Nações Unidas, em 2015, à aprovação, precisamente, quer da "Agenda 2030" quer dos “Objetivos de Desenvolvimento Sustentável 2030". E a verdade é que esta preocupação com o desenvolvimento sustentável tem sido já uma evidência também em países em que se fala português. Ora, assim, neste projeto cultural, cada grupo de trabalho teve, precisamente, de apresentar, com um vídeo até 3 minutos de duração, um exemplo de um projeto de desenvolvimento sustentável realizado num desses países.

Tabela 1 - Temáticas de projetos sobre desenvolvimento sust
Temática
- Combate às alterações climáticas, durante os
transportes de mercadorias
- Uso sustentável do capital natural por empresas e
setores da sociedade civil associados ao mar, nos
Açores
- Utilização do "European Solidarity Corps" para a
conservação da natureza
- Uso partilhado da bicicleta, em Lisboa

Refira-se, ainda, que cada grupo teve de escolher apenas um projeto específico, que se deveria inserir, mais especificamente, num dos objetivos seguintes: i) "objetivo 12: 
garantir padrões de consumo e de produção sustentáveis"; ii) "objetivo 14: adotar medidas urgentes para combater as alterações climáticas e os seus impactos".

Proposta 2. O projeto "Storytelling: quem conta um conto acrescenta um ponto", dinamizado com o objetivo principal de desenvolver as capacidades de escrita e o conhecimento da cultura lusófona, consistiu na elaboração, em grupos de trabalho, de um conto infantil que tivesse tido como mote um determinado provérbio popular lusófono, originário de países de língua portuguesa, previamente escolhido. Combinando o texto original com ilustrações disponíveis no Storybird $^{8}$ e selecionadas pelos alunos, cada grupo de trabalho apresentou, como resultado, um livro digital, sendo que todos os livros digitais criados foram, posteriormente, impressos e entregues a crianças a estudar português não só na cidade da universidade em questão como também em Angola e Cabo Verde. A tabela seguinte apresenta não só os títulos dos livros digitais criados como também os respetivos provérbios populares que de inspiração serviram.

Tabela 2 - Título dos livros infantis digitais criados e provérbios populares que serviram de inspiração

\begin{tabular}{|l|l|}
\hline Título do livro infantil produzido & Provérbio popular \\
\hline - As aventuras de Nicolau & Apenas as montanhas não se cruzam; as pessoas \\
- O dia em que o Rico nadou & Querer é poder \\
\hline - Otávio, o ouriço & As aparências iludem \\
- A esperança é a última que morre & A esperança é a última que morre \\
- A lição do Fernando Falador & Em boca fechada, não entra mosquito \\
\hline - Bons amigos & Diz-me com quem andas; e dir-te-ei quem és \\
\hline - Cão que ladra não morde & Cão que ladra não morde \\
\hline - Os meninos de Galoisinha & Água mole em pedra dura, tanto bate até que \\
& fura \\
\hline - Quem não tem cão... & Quem não tem cão... caça com gato \\
\hline
\end{tabular}

Proposta 3. O projeto "Uma aventura/Um dia em... - à descoberta de cidades lusófonas" foi também proposto com os objetivos anteriormente indicados: o desenvolvimento da escrita e o conhecimento do mundo lusófono. Porém, neste projeto, pretendeu-se já que os discentes aprofundassem o seu conhecimento sobre o espaço lusófono na atualidade. E, daí, portanto, ter-se solicitado que cada grupo de trabalho elaborasse um conto breve, e de tema livre, em que a ação decorresse numa cidade de um país lusófono.

\footnotetext{
${ }^{8}$ Disponível em: https://storybird.com/. Acesso em 20 fev. 2021.
} 
Tabela 3 - Títulos de contos com a ação a decorrer em países lusófonos

\begin{tabular}{|l} 
Título do conto \\
- Um dia... em Braga \\
- Um dia... Lagos \\
- Um dia... em Lisboa \\
- Um dia... em Peniche \\
- Um dia ... em Santarém \\
- Um dia... em Luanda \\
- Um dia... no Rio de Janeiro \\
- Um dia... em São Paulo
\end{tabular}

E a verdade é que a pesquisa feita pelos alunos, a respeito de cada uma das cidades escolhidas, fez com que cada texto abordasse temáticas tão distintas quanto ricas, como a exclusão social e as diferenças sociais, o que não deixou de alimentar também interessantes discussões, inclusive, na sala de aula. Elaborados os textos, foram estes entregues a alunos de escolas públicas da cidade da universidade em questão, e também a estudarem português, que ficaram responsáveis pelas ilustrações de cada conto. O resultado esperado consistiu também na elaboração de livros digitais, combinando-se, agora, os textos e as ilustrações, todos originalmente feitos por alunos, e a ficarem disponíveis para todos os discentes participantes.

\section{Conclusão}

Ainda que sejam recorrentes as afirmações de que o mundo está cada vez mais ligado, e o que não deixa, naturalmente, de ser verdade, atendendo-se, desde logo, aos múltiplos avanços da tecnologia que permitem uma globalização sem precedentes, não significa tal que se trate de uma evolução plenamente saudável, já que "a cidadania global acaba sendo apenas uma categoria que nos mostra o caminho e o comportamento a seguir, mas a escolha de incorporá-la é vulnerável à falta de empatia e à privação de conhecimento" (Jesus, 2016, p. 51). Ora, é precisamente neste contexto que advoga Jesus (2016, p. 51) que "a função da cultura aliada à linguagem pode então criar de maneira acessível e natural uma infraestrutura base para prossecução de uma integração harmoniosa e democrática" (JESUS, 2016, p. 51). Fora precisamente neste quadro que, e atendo-nos ao nosso trabalho com turmas de português como língua adicional, procurámos exemplificar como poderia uma abordagem pluricêntrica do português contribuir para que surgisse a sala de aula como um importante espaço fomentador de uma maior consciencialização dos aprendentes sobre o ativo papel que poderão cada vez mais assumir no mundo. E, perante as dificuldades que atualmente assolam a humanidade, e não apenas o espaço da lusofonia, a incorporação de uma maior preocupação cívica nas aulas, no nosso caso, de língua adicional afigura-se, na verdade, como determinante, para que uma educação de qualidade se possa cada vez mais cumprir (SEQUEIRA, 2016. E, na verdade, as reações que recolhemos, aliás, de forma informal, dos nossos alunos, a respeito dos trabalhos que apresentámos, não deixa de ser já 
per se um importante indicador de tal, nomeadamente, e a título apenas exemplificativo, com uma maior atenção não só às distintas variedades do português como também ao Outro, em todas as suas multiplicidades, correspondentes, também, aos distintos espaços geográficos que habita.

\section{Referências}

AA.VV. Mediación Intercultural, una propuesta para la formación. Madrid: Editorial Popular, 2008.

BARRETT, M. FOREWORD. In: BYRAM, M.; GOLUBEVA, I.; HUI, H. \& M. WAGNER (Eds.), From principles to practice in education for intercultural citizenship (). Reino Unido: Short Run Press Ltda, 2017, p. 7-10. https://doi.org/10.21832/9781783096565-001

BYRAM, M. Intercultural Competence in Foreign Languages - The intercultural speaker and the pedagogy of foreign language education. In: DEARDORFF, D. The sage Handbook of Intercultural Competence. Los Angeles, London, Nova Delhi, Singapore, Washington DC: Sage Publications, 2009, p. 321-332.

CARDOSO, S. Uma língua que acolhe: desafio para os professores de português na inclusão das crianças refugiadas. 2017. 120 f. Dissertação de mestrado. Lisboa: Universidade Aberta, 2017.

CARIDE, J. A. La mediación como pedagogía social: viejas realidades, nuevos desafíos para la intervención social. In: VIEIRA, R. V. MARQUES, J. SILVA, P. VIEIRA, A. \& MARGARIDO, C. (Eds.), Pedagogias de mediação intercultural e intervenção social. Porto: Edições Afrontamentos., 2016, p. 13-26.

CONSELHO EUROPEU. Quadro Europeu Comum de Referência para as línguas: aprendizagem, ensino e avaliação. Lisboa: Edições ASA, 2001.

CONSELHO DA EUROPA. Competences for democratic culture. Living together as equals in culturally diverse democratic societies. Estrasburgo: Conselho da Europa, 2016.

CONSELHO DA EUROPA. The common European framework of reference for languages: learning, teaching and assessement. Companion volume with new descriptors. Estrasburgo: Conselho da Europa, 2018. Disponível em: https://tinyurl.com/ybjrszaa. Acesso em: 29 jul. 2020.

EDNIR, M. A Brazilian View on Global Citizenship Education. Global Education Magazine, p. 68-73, 2015. https://doi.org/10.4324/9781315683492-11

FANTINI, A. E. Assessing intercultural competence: issues and tools. In: DEARDORFF, D. K. (ed.). The Sage Handbook of Intercultural Competence. Thousand Oaks: Sage, 2009, p. 456476.

FERNANDES, E.; Silva, R. A adoção de uma abordagem eclética: da avaliação diagnóstica à elaboração de um syllabus orgânico em turmas mistas com falantes/aprendizes de português como língua herança. In: OSÓRIO, P. \& GONÇALVES, L. Ensino do português como LNM. Metodologias, estratégias e abordagens de sucesso. Rio de Janeiro: Dialogarts, 2019, p. 307-335. 
JESUS, M. P. de. Cidadania global: uma construção cultural e linguística. C@LEA - Revista Cadernos de Aulas do LEA, n.o 5, p. 43-52, 2016.

JOUÊT-PASTRÉ, C. Variação e Políticas Linguísticas: Desafios no Ensino de Português como Língua Estrangeira. In: FERREIRA, J. P. \& MARUJO, M. (eds.). Ensinar Português nas Universidades da América do Norte. Toronto: University of Toronto \& Instituto Camões, 2010, p. 189-195.

MATTOS, A. M. A. Novos letramentos, ensino de língua estrangeira e o papel da escola pública no século XXI. Revista X, v. 1, n. 1, p. 33-47, 2011.

https://doi.org/10.5380/rvx.v1i1.22474

MELO-PFEIFER, S. Português como língua de herança.Domínios de Lingu@gem, 12(2), p. 1161-1179, 2018. https://doi.org/10.14393/DL34-v12n2a2018-18

MENDES, E. O ensino do português como língua estrangeira (PLE): desafios, tendências contemporâneas e políticas institucionais. In: ANDREEVA, Y. (org.). Horizontes do saber filológico. Sófia-Bulgária: Sveti Kliment Ohridski, 2014, p. 33-45.

OLIVEIRA, G. M. Language Policy and Globalization: The Portuguese language in the twentyfirst century. In: MOITA-LOPES, L. (ed.). Global Portuguese - Linguistic Ideologies in Late Modernity. New York \& London: Routledge, 2015, p. 27-46.

OLIVEIRA, G.; JESUS, P. Ensinando línguas em uma perspectiva pluricêntrica: o Portal do Professor de Português Língua Estrangeira/Língua Não Materna (PPLE). Domínios da Linguagem, v. 12, n. 2, p. 1043-1070, 2018. https://doi.org/10.14393/DL34-v12n2a2018-13

ORTIZ, R. A.; FINARDI, K. R. Social inclusion and CLIL: evidence from La Roseraie. In: International Conference on Education, Research and Innovation. ICERI 2015 Proceedings. Madrid: IATED, v. 1, p. 7660-7666, 2015.

RATO, A.; GRAÇA, L. Uma abordagem pluricêntrica no ensino do português como língua adicional. In: DOMINIQUE, N., \& Neto, M. (ed.), Microgeopolítica da língua portuguesa: ações, desafios e perspectivas. Boavista Press (no prelo).

REIMERS, F. Empoderar crianças e jovens para a cidadania global, 2017.

Disponível em: $\quad$ www.fmss.org.br/wpcontent/uploads/2017/12/EmpoderandoAlunosParaMelhoraroMundo.pdf. Acesso em: 29 jul. 2020.

SEQUEIRA, R. M. Interculturalidade crítica e globalização. In: LUNA, J. M. F. (Ed.), Internacionalização do currículo: educação, interculturalidade e cidadania global. Campinas: Pontes Editores, 2016, p. 55-70

SIGNORINI, I. Portuguese Language Globalism. In: MOITA-LOPES, L. (ed.). Global Portuguese - Linguistic Ideologies in Late Modernity. New York \& London: Routledge, 2015, p. 47-65.

SOLLAI, S.; PARMA. A. As línguas portuguesas do mundo: representações pluricêntricas de Português Língua Estrangeira (PLE) numa amostra de material didático. Hispania, 101(2), p. 237-248, 2018. https://doi.org/10.1353/hpn.2018.0116

TILIO, R. C. Língua estrangeira moderna na escola pública: possibilidades e desafios. Educação \& Realidade, v. 39, n. 3, p. 925-944, 2014. https://doi.org/10.1590/S2175$\underline{62362014000300016}$ 
VIEIRA, A.; VIEIRA, R. Pedagogia social, mediação intercultural e (trans)formações. Porto: Profedições, 2016.

Recebido em: 26/08/2020.

Aceito em: 22/10/2020. 